\title{
Comparative In Vitro Osteoinductivity Study of CaP Ceramics (HA, $\alpha$-TCP, $\beta$-TCP) Using 10T1/2 Cells with Different Controls and Possible Correlations with Other Systems
}

\author{
Juliana Tsz Yan Lee ${ }^{1}$, Kefeng Wang ${ }^{2}$, Wai Hung Tsang ${ }^{3,4}$, King Lau Chow ${ }^{1,3,4}$ \\ ${ }^{1}$ Bioengineering Graduate Program, The Hong Kong University of Science and Technology, Hong Kong, China; ${ }^{2}$ Department of \\ Mechanical Engineering, The Hong Kong University of Science and Technology, Hong Kong, China; ${ }^{3}$ Department of Biology, The \\ Hong Kong University of Science and Technology, Hong Kong, China; ${ }^{4}$ Division of Life Science, The Hong Kong University of \\ Science and Technology, Hong Kong, China. \\ Email: juliana@ust.hk
}

Received November $3^{\text {rd }}, 2010$; revised January $20^{\text {th }}, 2011$; accepted February $12^{\text {th }}, 2011$.

\begin{abstract}
In this study, we used a pluripotent mesenchymal stem cell (MSC) model, C3H/10T1/2, to evaluate three calcium phosphate $(\mathrm{CaP})$ materials, namely the hydroxyapatite $(H A), \alpha$-tricalcium phosphate $(\alpha-T C P)$ and $\beta$-tricalcium phosphate $(\beta-T C P) .10 T 1 / 2$ cell was chosen as it has advantages over its counterparts in terms of ease of maintenance, free of ethical concerns and also more reproducible results. ALP enzymatic assay, $R T-q P C R^{b}, D A P I^{c}$ staining and $S E M^{d}$ were employed to assess the osteoinductivity of these materials. A good reference material which also acts as a scientific control ${ }^{e}$ is necessary for comparisons of results from different experimental batches and hence other materials such as titanium, Nunclon ${ }^{T M} \Delta$ plastic surface, BD Falcon ${ }^{T M}$ plastic surface and gold coated porous $H A$ were also tested. The results show that ceramics induce a more sustained osteo-differentiation state as compared with plastics. Inductivity was found to be acting in descending order of strength with $H A>\beta-T C P>\alpha-T C P$, which is reversed in terms of their impact on proliferation rate $(H A<T C P)$. This is also consistent with the results observed in SBF study in terms of calcium phosphate precipitate area coverage $(H A>T C P)$ and in vivo osteoinductivity in terms of incidence and quality of bone described previously (HA $>\beta-T C P>\alpha-T C P$ ). These confirm the suitability of using 10T1/2 cells in cell culture assay of osteoinductivity.
\end{abstract}

Keywords: Bone Tissue Engineering, Stem Cell, Calcium Phosphate, Hydroxyapatite, Gene Expression, Osteoinductivity, In Vitro Test, PCR (Polymerase Chain Reaction), SEM (Scanning Electron Microscopy)

\section{Introduction}

Many calcium phosphate materials have been proven to be osteoconductive, which refers to the ability of the material to support the growth of osteoblasts [1]. In contrast, osteoinductivity, which is the ability of a material to induce undifferentiated cells into the osteo-lineage [1-3], is an aspect that remains controversial. The osteoinductive property of a material is usually demonstrated by bone formation after implantation in non-osseous sites (e.g., subcutaneously or in intramuscular sites) [4]. It is the most direct way of assessing osteoinductivity but in vitro assays are highly preferred due to lower cost, shorter experiment time and ethical issues. This requires the use of totipotent or pluripotent cells. Adult stem cell such as mesenchymal stem cell (MSC) model is a good candidate due to its multipotency, relative ease of maintenance and free of ethical concerns [5-8]. In this study, we used $\mathrm{C} 3 \mathrm{H} / 10 \mathrm{~T} 1 / 2$ cell as it possesses the properties of MSC yet it is an established cell line that may provide more reproducible results as compared to commonly used pri-

${ }^{\mathrm{a}} \mathrm{ALP}$ : alkaline phosphatase; ${ }^{\mathrm{b}} \mathrm{RT}$-qPCR: reverse transcription - quantitative (real time) polymerase chain reaction; ${ }^{\mathrm{C} D A P I}$ : 4',6-diamidino-2phenylindole; ${ }^{\mathrm{d}}$ SEM: scanning electron microscopy; ${ }^{\mathrm{e}} \mathrm{S}$ cientific control: The control group is practically identical to the treatment group, except for the single variable of interest whose effect is being tested. In bioassays for materials on osteoinductivity, the reference material is expected to be inert and can also act as a reference point; ${ }^{\mathrm{f}} \mathrm{SBF}$ : simulated body fluid. 
mary stem cell the purity of which is difficult to control precisely in different batches of experiments.

In in vitro assays, osteo-markers such as runt-related transcription factor 2 (Runx2, also denoted as Cbfa1), alkaline phosphatase $\left(A l p\right.$ or $\left.\mathrm{ALP}^{\mathrm{a}}\right)$, collagen I (Col1) and osteocalcin $(\mathrm{Ocn})$ are often monitored to evaluate the osteoinductivity. Whether a material is osteoinductive is determined by comparing the marker gene expression of cells on the sample materials with that on a reference material, ideally an inert material. Enhanced osteo-marker expression is expected to be observed from an osteoinductive material. Thus we also experimented on titanium and gold coated porous HA as the reference material. Furthermore, a suitable choice of reference material would allow us to compare results from different batches of experiments to a certain extent indirectly. In general, tissue culture plastic from a given supplier has relatively consistent surface properties and readily obtainable as compared to materials synthesized in different batches in small scale. Hence we compared the Alp expression of cells on bioceramics with plastics.

On the other hand, although cell line has many advantages over primary cells recovered from animals, it is not a suitable choice unless it produces consistent conclusions with in vivo study. Therefore, we analyzed our results with previous in vivo bone formation study [9]. In order to make reliable comparisons, the materials used in this project were synthesized in the same institute as in the previous report and made by the same method. The comparison with SBF study was also included for reference.

The ultimate goal of this study is to evaluate the osteoinductivity of calcium phosphate ceramics through $10 \mathrm{~T} 1 / 2$ cell culture assays with investigation of different control materials. The possible correlations with SBF study and in vivo osteoinductivity were also discussed.

\section{Materials and Methods}

\subsection{Material Synthesis}

HA, $\alpha$-TCP and $\beta$-TCP were synthesized by foaming method using $5 \%$ hydrogen peroxide $\left(\mathrm{H}_{2} \mathrm{O}_{2}\right)$ solution as described [9]. The dried calcium phosphate cylinders were sintered using programmed oven and then cut with a diamond saw into circular discs of $1 \mathrm{~mm}$ thickness and $10 \mathrm{~mm}$ diameter. The average porosity is about $71 \%$ $77 \%$ with macro-pores ranging from 50 to $500 \mu \mathrm{m}$.

\subsection{Material Characterization and Sterilization}

The phases of different material surfaces were identified using an X-ray diffractometer (XRD) (PW1830,

${ }^{a}$ Alp denotes the gene that codes for alkaline phosphatase in mouse and ALP denotes the alkaline phosphatase protein according to the gene nomenclature convention adopted in the biology field.
Philips). Measurements were performed using a $\mathrm{Cu}-\mathrm{K} \alpha$ X-ray source and the XRD spectra matched with the database using X'Pert HighScore Plus version 2.0. The discs of materials were sterilized by autoclaving at $121^{\circ} \mathrm{C}$ for $20 \mathrm{~min}$ and dried in a $80^{\circ} \mathrm{C}$ oven. The chemical composition of samples after autoclave sterilization treatment was also analyzed by an energy dispersive X-ray spectrometer (EDX) equipped with a scanning electron microscope (JSM-6390, JEOL, Japan). The phase of the materials was confirmed again by X-ray diffraction (XRD) before cell plating.

\subsection{Gene Expression Study}

\subsubsection{Cell Subculturing}

$\mathrm{C} 3 \mathrm{H} / 10 \mathrm{~T} 1 / 2$ cells (CCL-226 ${ }^{\mathrm{TM}}$, ATCC) were cultured in $10 \mathrm{~cm}$ culture dishes (Nunc) containing Dulbecco's Modified Eagle Medium (DMEM, Invitrogen) supplemented with $10 \%$ fetal bovine serum (FBS) and antibiotics $(100 \mathrm{U} / \mathrm{mL}$ penicillin and $100 \mu \mathrm{g} / \mathrm{mL}$ streptomycin) in a tissue culture incubator at $37^{\circ} \mathrm{C}$ with $5 \% \mathrm{CO}_{2}$. At $95 \%$ confluence, the cells were trypsinized, resuspended in complete medium (DMEM with FBS and antibiotics) and counted in a hemocytometer to evaluate the cell density. Then the cells were plated for the assays and medium changed at every three days.

\subsubsection{ALP Enzymatic Assay with Powder}

$3 \times 10^{4}$ cells/well were seeded in 96 well plates (Nunc) with and without $1 \mu \mathrm{L} 2.5 \%(\mathrm{v} / \mathrm{v}) \mathrm{HA}$ powder or $\beta$-TCP powder added. After 2 days, the medium was removed and the wells were rinsed 3 times with phosphate buffer saline (PBS). $50 \mu \mathrm{L}$ of $0.2 \%$ Triton $\mathrm{X}-100$ was added to each well and shaken at $500 \mathrm{rpm}$ for $30 \mathrm{~min}$. The lysate was mixed with $50 \mu \mathrm{L} 1 \mathrm{mM}$-nitrophenyl phosphate (Sigma) substrate solution. Absorbance at $405 \mathrm{~nm}$ was measured. The absorbance of the wells without cells plated was used as the background control. A total of three independent assays were carried out with each assay performed in replicates. Calibration was performed with $p$-nitrophenol (Sigma).

\subsubsection{RT-qPCR}

$9 \times 10^{4}$ cells were seeded on each disc in 48 well plates (Nunc). Wells without materials added (plastic surfaces) were used as controls. RNA from the cells was extracted by TRIzol at day 3,6 and 12 according to the manufacturer's instruction. For cells on the $\mathrm{CaP}$ materials, modifications were made to the RNA extraction protocol as described previously [10]. The subsequent DNase1 treatment, reverse transcription and qPCR were also performed as described [10]. In the qPCR experiments, a calibrator was used for each qPCR batch so that the results from different batches can be compared. 


\subsection{Cell Proliferation Rate and Distribution by DAPI Staining}

$9 \times 10^{4}$ cells were seeded on each disc in 48 well plates (Nunc). At day 1 and day 3, the discs were washed with PBS and then fixed by $4 \%$ paraformaldehyde (Sigma) for $5 \mathrm{~min}$ at $4{ }^{\circ} \mathrm{C}$. The permeability of cells on the discs was increased by washing 3 times in $0.1 \%$ Triton X-100. 4',6-diamidino-2-phenylindole (DAPI) stain was applied to the discs at $1 \mu \mathrm{g} / \mathrm{mL}$ in $0.1 \%$ Triton $\mathrm{X}-100$ for $5 \mathrm{~min}$, followed by washing with Triton X-100. Fluorescence images were taken using Olympus upright fluorescence microscope BX41. 3 discs were used for each sample type and 5 spots were randomly chosen from each disc. 5 to 15 images were taken for each spot due to the limitation of the depth of field of the microscope and cells lying at different depths. The images were then processed by ImageJ to obtain a clearer image and quantified using computer software AlphaEaseFC.

\subsection{Mineralisation Study by Scanning Electron Microscope (SEM)}

$9 \times 10^{4}$ cells were seeded on each disc in 48 well plates (Nunc). At day 7, the cells on the discs were washed with PBS and then fixed by $2.5 \%$ glutaraldehyde (Sigma). The discs were then rinsed with double distilled water and quickly frozen by dipping into liquid nitrogen. The frozen samples were transferred to punctuated microcentrifuge tubes and freeze dried overnight. A layer of gold of about $20 \mathrm{~nm}$ thickness was sputtered on the material surface with silver paint to connect the top surface to the carbon tape. SEM images were captured at $15 \mathrm{kV}$ accelerating voltage and $12 \mathrm{~mm}$ working distance using scanning electron microscope (SEM) (JSM-6390, JEOL, Japan).

\subsection{Statistical Analysis}

P-values were calculated using two-tailed Student's t-test of unequal variance using Excel.

\section{Results}

\subsection{Material Characterization}

The chemical composition of the synthesized materials was characterized by EDX and the phase by XRD. Table 1 shows the approximate quantification of the relative element concentrations. The three major elements of the materials $(\mathrm{Ca}, \mathrm{P}$ and $\mathrm{O})$ were detected and their concentrations are roughly equal to the theoretical values. There is a minute amount of carbon detected on the samples and this may be due to the adsorption of carbon dioxide on the material surfaces. Another possibility is that car
Table 1. Quantification of elements in autoclaved HA, $\alpha$-TCP and $\beta$-TCP detected using EDX (The calculated theoretical atomic \% based on the chemical formula was shown in the bracket).

\begin{tabular}{cccccc}
\hline Atomic $\%$ & $\boldsymbol{O}$ & $\boldsymbol{C} \boldsymbol{a}$ & $\boldsymbol{P}$ & $\boldsymbol{C}$ & $\boldsymbol{A} \boldsymbol{u}$ \\
\hline HA & $57(59.1)$ & $25(22.7)$ & $13(13.6)$ & $3(0)$ & $2(0)$ \\
$\alpha$-TCP & $56(61.5)$ & $24(23.1)$ & $15(15.4)$ & $3(0)$ & $2(0)$ \\
$\beta$-TCP & $54(61.5)$ & $25(23.1)$ & $14(15.4)$ & $4(0)$ & $3(0)$ \\
\hline
\end{tabular}

bonate calcium phosphates are formed. Gold was detected since gold was coated on the scaffold surface to reduce the charging effect during the measurements. Figure 1 shows the XRD spectra of the bioceramics. The peaks match the most intense peaks of the database. Together with the EDX results, the identities of the materials were confirmed.

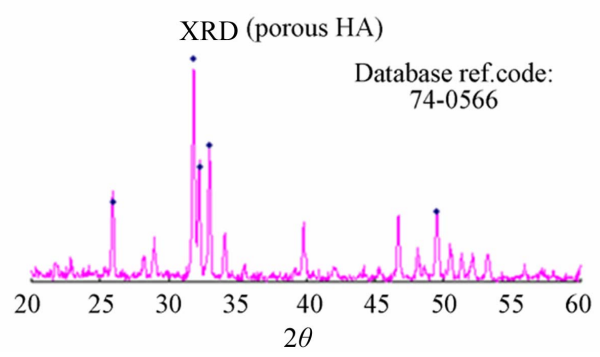

(a)

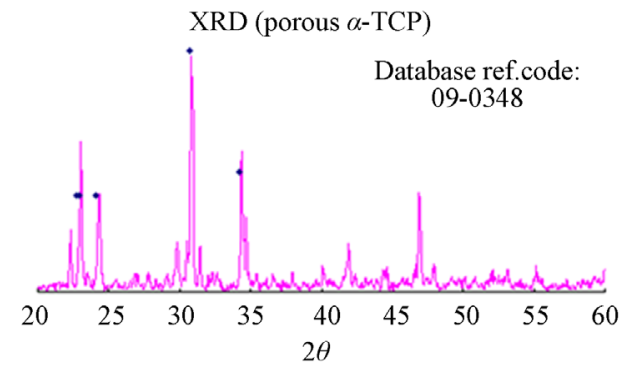

(b)

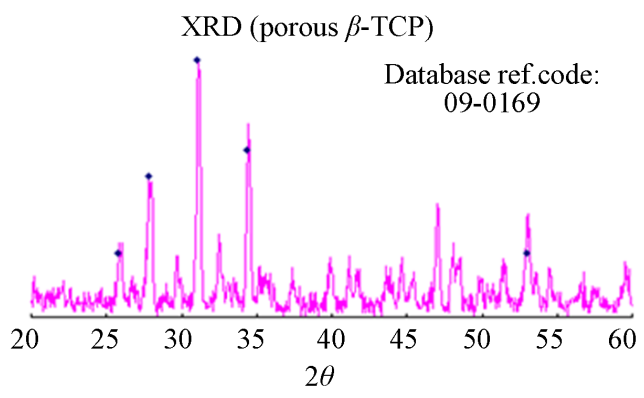

(c)

Figure 1. XRD spectra of porous (a) HA, (b) $\alpha$-TCP and (c) $\beta$-TCP and the corresponding matches from the database. 


\subsection{In Vitro Osteoinductivity Study Using 10T1/2 Cell Assay}

Osteogenic development can be classified into 3 stages: proliferation, bone differentiation and bone mineralizetion [11]. Bone differentiation process can be used to indicate osteoinductivity. Thus, the markers defining the bone differentiation were monitored by both the ALP enzymatic assay and the RT-qPCR to evaluate the gene expression levels. In addition, when cells get more differentiated, they would proliferate less and become more mineralized. Hence proliferation was also monitored by DAPI staining and mineralization by SEM study.

\subsubsection{ALP Enzymatic Assay}

This enzyme assay evaluates ALP expression at protein level. Figure 2 shows the ALP activity of 10T1/2 cells cultured with and without HA or $\beta$-TCP powder. The low ALP activity in the "No cell" control' indicates the background ALP activity due to the adsorbed ALP from the complete cell culture medium (with serum) was low. The ALP activity of cells cultured with HA powder is higher than that of cells cultured with $\beta$-TCP powder, suggesting the osteoinductivity of HA may be higher than $\beta$-TCP. At this cell plating density, the ALP activity is lower with the addition of HA powder or $\beta$-TCP powder (comparing the "No material" control' with "Cells with HA" and "Cells with $\beta$-TCP"). Though powder is not normally used in bone implant applications directly, ALP enzymatic assay using bioceremic powder may serve as a preliminary study as HA shows higher ALP expression in both enzymatic assay and RT-qPCR experiments (to be presented in the next section) than TCP, i.e. the results from the two studies are consistent.

\subsubsection{RT-qPCR}

RT-qPCR estimates Alp expression at mRNA level. Standard Taqman ${ }^{\circledR}$ Gene Expression Assays were used instead of self-designed primers as it would allow the experiments to be reproduced from other researchers more easily, which is desirable for the standardization of assays in future.

Figure 3 shows the relative gene expression of 10T1/2 cells on different ceramics. Comparing the effect of different materials, there is no significant difference in expression of $C b f a l$ from cells grown on different types of materials on day 3 , day 6 and day 12 . The $C b f a l$ expression is relatively stable across different periods. $C b f a l$ is the transcription factor regulating $O c n$ expression and it is well accepted as the master switch of osteogenesis $[12,13]$. The Coll gene is found to display an expression level in a descending order of HA $>\beta$-TCP $>\alpha$-TCP at day 6 and there is a slight increase in expression with time. The gene expression difference is rather small as

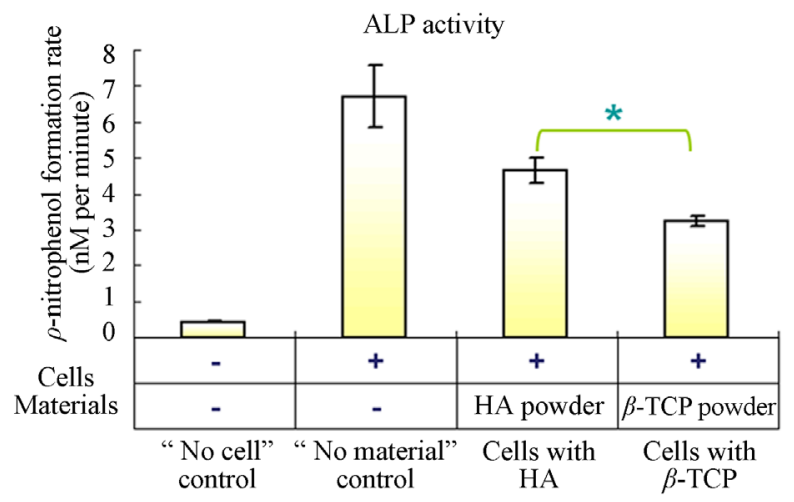

Figure 2. ALP activity of 10T1/2 cells cultured with and without HA or $\beta$-TCP powder $(n=10$; mean \pm SEM) $(* p<$ 0.05).

compared with Alp.

The $\mathrm{A} l p$ expression increases significantly with time from day 3 for all materials under study and the increase is larger for the calcium phosphate materials than theplastic control. Besides, the Alp appears to be a better marker for comparing the osteoinductivity as contrasted to others for monitoring the effect of different materials. Using Alp expression as an indicator, HA is more inductive to the marker expression. The effect follows the order of HA $>\beta$-TCP $>\alpha$-TCP, which is similar to that observed using Coll, although the magnitude of signal change is greater with Alp monitored.

The Ocn expression, which is expected to increase with time, does not show much increase during the culture period, which will be discussed in section 4.3.

\subsubsection{DAPI Staining}

To evaluate how different materials affect the cell proliferation, the number of cells on the materials were monitored using DAPI staining. DAPI is a fluorescent stain that binds strongly to DNA and stains the nuclei of cells. Hence it allows the cells to be detected under microscope. Figure 4(a) shows the distribution of 10T1/2 cells which attach to nearly the entire surface of the scaffolds made of all three materials, HA, $\alpha$-TCP and $\beta$-TCP. Each blue dot in the photos represents a single cell. The density of cells is higher on the cross-sections of the scaffolds than in the middle of the pores due to the higher roughness of these regions compared with the pore inner surfaces. It was noted that more cells are present on the TCP discs than on the HA discs for both day 1 and day 3 .

In order to obtain the quantified result of the cell number on the scaffolds, the number of cells on the photos was counted and the number plotted in Figure 4(b). There is little cell proliferation for cells on HA from day 1 to day 3 while there is significant proliferation observed in cases of using $\alpha$-TCP and $\beta$-TCP as the substrates. 

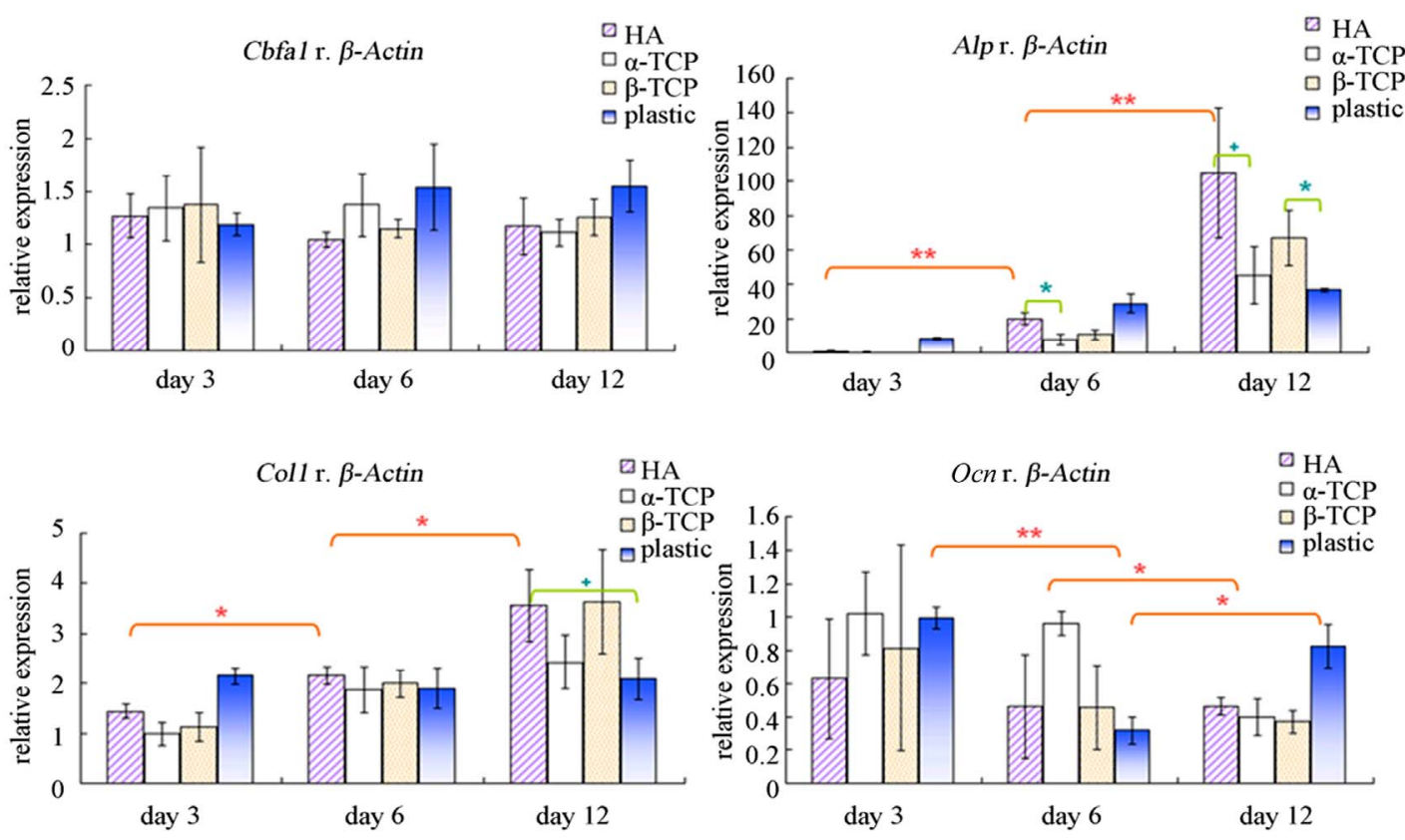

Figure 3. Relative quantification of gene expression of Cbfal, Alp, Coll and Ocn in 10T1/2 cells seeded on HA, $\alpha$-TCP and $\beta$-TCP after 3, 6 and 12 days in culture. Wells in the culture plate without materials (Nunclon ${ }^{\mathrm{TM}} \Delta$ plastic surface) were used as reference materials. (cDNA used for $O c n$ quantification was double that of other genes) $(n=3$ replicate discs in cell plating; mean \pm SD) $(+p<0.1, * p<0.05, * * p<0.005)$.
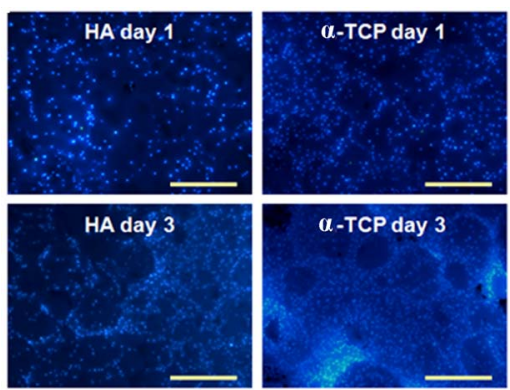

(a)

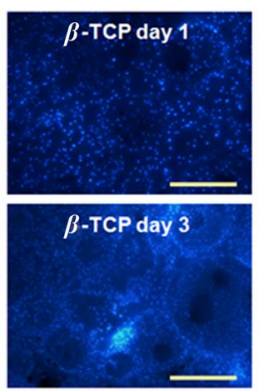

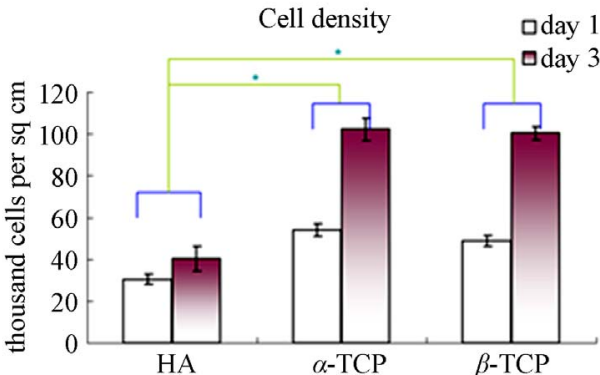

(b)

Figure 4. (a) Distribution of 10T1/2 cells on HA, $\alpha$-TCP and $\beta$-TCP with DAPI staining using a $4 X$ objective and images processed with extended depth of field in ImageJ (scale bar $=500 \mu \mathrm{m}$; Each blue dot represents a single cell) (b) Cell numbers on HA, $\alpha$-TCP and $\beta$-TCP at day 1 and 3 quantified from images with DAPI staining $(n=15$ spots on three discs; mean \pm SEM) $\left({ }^{*} \mathbf{p}<0.05\right.$ for the proliferation rate of cells on $\alpha$-TCP and $\beta$-TCP compared with HA).

These results imply that the degree of differentiation of cells on HA is higher than that on TCP, and this notion is consistent with the observed change of Alp expression in these different materials.

\subsubsection{Morphology by SEM}

Figure 5 shows the morphology of 10T1/2 cells on HA, $\alpha$-TCP and $\beta$-TCP revealed by SEM. After 1 week of culture, the cells attached and grew on the materials. They form a layer across the pores and "nodules" implicating nucleation of mineralization were observed in some areas for all three materials, indicating that these materials may enhance mineralization.

\section{Discussion}

\subsection{Effects of Dissolution on Gene Expression}

It has been suggested that calcium and phosphate ions would influence cell behavior and differentiation [14-21]. It is widely accepted that $\beta$-TCP can be resorbed in vivo and we may initially expect there would be ions dissolved from the $\beta$-TCP, which would affect gene expression. This dissolution from HA or $\beta$-TCP was observed in a number of studies when $\mathrm{Ca}$ and $\mathrm{P}$ free solutions were used [22-26]. 
However, the physiological fluid is indeed supersaturated with respect to the solubility of HA or $\beta$-TCP from calculations based on methods described by Lu et al. [27]. Chen et al. [22] and Suzuki et al. [26] have also demonstrated that the $\mathrm{Ca}$ concentration in the immersion medium decreases with time using either SBF or cell culture medium respectively. These observations suggest that macroscopic dissolution of HA or $\beta$-TCP in cell culture medium without the action of cells is negligible.

In this study, the medium is changed regularly to keep the composition of cell culture medium as constant as possible. A continuous flow system or a larger volume of medium may be used in further studies to keep the change in ion concentrations minimal.

\subsection{Osteoinductivity of HA, $\alpha$-TCP and $\beta$-TCP}

In general, HA has higher osteoinductivity compared with TCP based on the gene expression and proliferation rate analysis. This indicates HA may be a better material than TCP in inducing bone formation. On the other hand, the cells under the condition of higher osteo marker expression have lower proliferation rate. In other words, choosing materials which render the MSCs to have low proliferation rate or inhibiting the proliferation may be a possible means to achieve a higher degree of osteo-differentiation.

Furthermore, it is interesting to note that the Alp expression of cells on $\alpha$-TCP is different from that on $\beta$-TCP. $\alpha$-TCP and $\beta$-TCP have exactly the same chemcal formula $\mathrm{Ca}_{3}\left(\mathrm{PO}_{4}\right)_{2}$ [28-30] but differ in terms of physical properties. $\alpha$-TCP has monoclinic space groups while $\beta$-TCP has rhombohedral space groups [28] and $\alpha$-TCP has higher solubility than $\beta$-TCP $[28,30]$. In mineralization, adenosine-5'-triphosphate (ATP) is hydrolyzed by nucleoside triphosphate pyrophosphohydrolase (NTPPPH) to adenosine monophosphate (AMP) and inorganic pyrophosphate $\left(\mathrm{PP}_{\mathrm{i}}\right)$, which gets further degraded to yield inorganic phosphate $\left(\mathrm{P}_{\mathrm{i}}\right)$ by alkaline phosphatase (ALP). The inorganic phosphate thus generated forms apatite in the presence of calcium in the extracellular fluid [31]. The local microscopic environment (such as $\mathrm{pH}$ ) may be modified by cells and a lower $\mathrm{pH}$ would increase the calcium phosphate solubility. The phosphate concentration on $\alpha$-TCP surface may be higher than $\beta$-TCP due to its higher solubility, thus less alkaline phosphate is required to provide the inorganic phosphate. Besides, the cells may sense $\alpha$-TCP differently from $\beta$-TCP due to the crystal structure difference.

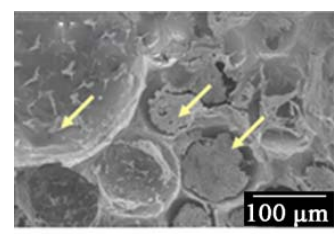

(a) HA at $100 \mathrm{X}$

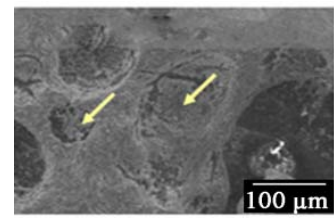

(d) $\alpha$-TCP at $100 \mathrm{X}$

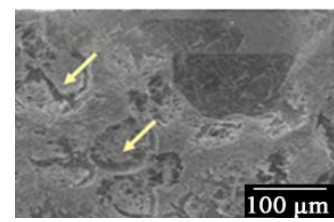

(g) $\beta$-TCP at $100 \mathrm{X}$

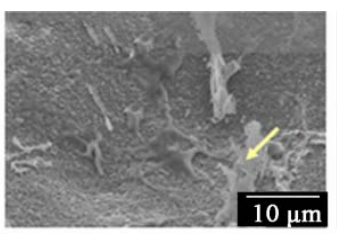

(b) HA at $1 \mathrm{kX}$

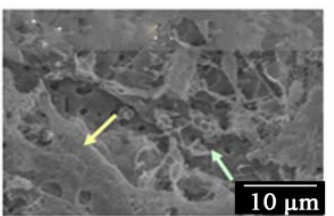

(e) $\alpha$-TCP at $1 \mathrm{kX}$

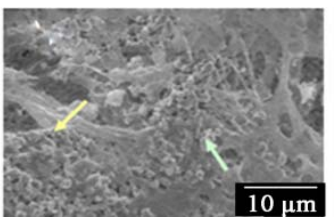

(h) $\beta$-TCP at $1 \mathrm{kX}$

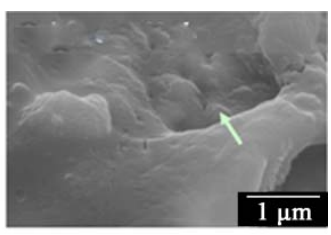

(c) $\mathrm{HA}$ at $10 \mathrm{kX}$

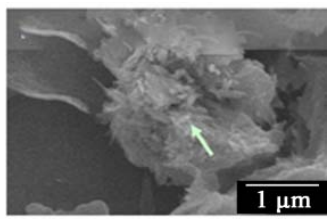

(f) $\alpha$-TCP at $10 \mathrm{kX}$

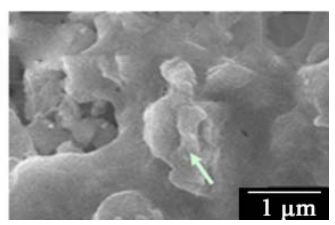

(i) $\beta$-TCP at $10 \mathrm{kX}$

Figure 5. Morphology of 10T1/2 cells on (a-c) HA, (d-f) $\alpha$-TCP and (g-i) $\beta$-TCP revealed by SEM at 100 X, 1 kX and $10 \mathrm{kX}$ magnifications at day 7 (The downward yellow arrows indicate the cells and the upward green arrows indicate the mineralized structures formed). 


\subsection{Gene Expression of Cells on Plastic and Effects of Osteogenic Supplement Addition}

Moving a step forward to the understanding of the chosen 10T1/2 cell culture assay system, the expression of cells on other control surfaces and the effect of osteogenic supplements were further studied. Since the Alp expression of cells on plastic is higher than the ceramics at day 3, controls other than Nunclon ${ }^{\mathrm{TM}} \Delta$ plastics were also tested. These include titanium, BD Falcon ${ }_{\mathrm{TM}}$ plastics and gold coated porous HA. Titanium has been successfully used as biomaterials [32] but without reported osteoinductivity. $\mathrm{BD}$ Falcon ${ }_{\mathrm{TM}}$ culture plate has surface chemistry different from Nunclon ${ }^{\mathrm{TM}} \Delta$ surface, which may induce osteo-differentiation. Gold coating on porous HA discs may allow the chemistry to be studied with less consideration in the surface topography difference [33].

Figure 6 shows that cells on HA have lower Alp expression compared with all other chosen materials, which seems to suggest HA has lower osteoinductivity compared with other materials. The lower Alp expression of cells on sample materials compared with plastics was also observed in some results from other groups $[34,35]$. When we take a closer look on the Alp and Coll expression at day 12, HA shows higher expression than plastic even though ceramics show lower Alp expression compared with plastics in short culturing period (day 3 andday 6). This suggests that the surface of plastic may be better to trigger the osteo-differentiation earlier compared with ceramics, but ceramics are better in sustaining the differentiation process. It would be interesting to investigate what the surface properties of tissue culture plastics are that render it more osteoinductive in short culture period. Besides, it should be noted that the Alp expression levels of cells on plastic surfaces from the two different suppliers are different.

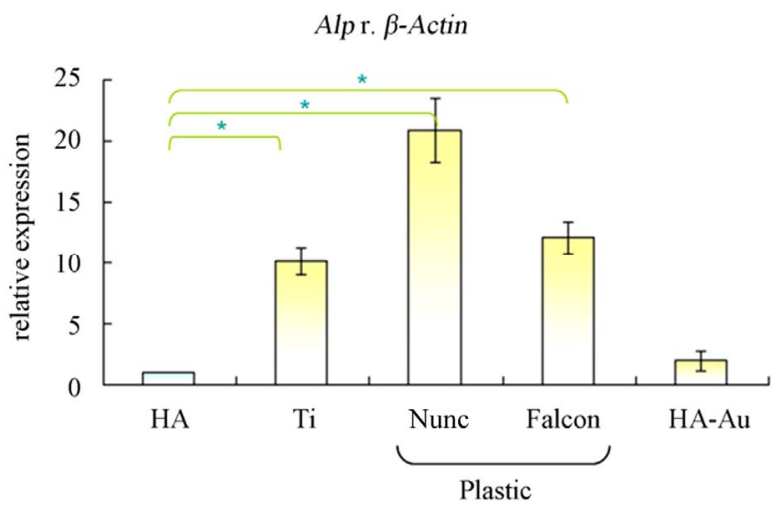

Figure 6. Gene expression on other materials at day 3 showing comparisons among porous HA, titanium, plastics of different brands (Nunc and Falcon) and gold coated porous HA $(n=2$ PCR replicates, mean \pm SD) $(* p<0.05)$.
On the other hand, Ocn expression has been demonstrated to be higher when ascorbic acid and/or dexamethasone is added as the osteogenic supplements $[11,36]$. Thus we did follow up experiments with and without the addition of $50 \mu \mathrm{g} / \mathrm{mL} L$-ascorbic acid and $10_{-8} \mathrm{M}$ dexamethasone to investigate the cause of the relative low Ocn expression. The use of osteogenic supplements elevated the Alp expression on $\mathrm{CaP}$ materials (Figure 7(a)), causing a larger difference among different $\mathrm{CaP}$ materials and this may facilitate the quantification. Nevertheless, the addition of osteogenic supplements enhanced the Ocn expression of cells on plastics significantly but not for cells on the ceramics (Figure 7(b)), indicating the lack of osteogenic supplements is not the major cause of the low Ocn expression. Other possible causes of the low Ocn expression may be the much higher stiffness of hydroxyapatite than required by Ocn production [37] or non-matching primers for the Ocn transcript isoform from $10 \mathrm{~T} 1 / 2$ cells due to a variety of Ocn isoforms [38,39].

\subsection{Correlation Analysis}

The predictability of material bioactivity using less complex systems was also assessed. Table 2 shows the summary of effects of different ceramics and by comparing results of different systems, there are correlations among the three systems under analysis (1. SBF study; 2. cell culture study and also 3 . in vivo bone formation). The rationale behind the correlations was given in the supplementary information. This possible correlation confirms that $10 \mathrm{~T} 1 / 2$ cell culture can be used as an easier and more reproducible means for studying in vitro osteoinductivity.

\section{Conclusions}

The following conclusions were drawn from this study: (1) Among the chosen ceramics, HA shows higher osteoinductivity by marker gene expression analysis and proliferation study as compared with those done with TCPs. (2) Inhibiting the proliferation of MSCs may be a possible means to achieve higher degree of osteo-differentiation. (3) After experimenting with different control materials, we concluded that plastic induced higher osteo-marker expression at the initial stage but ceramics induced a more sustained osteo-differentiation state compared with plastic. (4) Besides, the use of osteogenic supplements may enhance Alp expression, causing a larger difference among different materials and facilitates the quantification. (5) By comparing with the results of SBF study and in vivo bone formation described in other reports, the 10T1/2 cell culture system (under well cotrolled conditions) correlates with these systems. This 
Table 2. Summary of results from different assay systems.

\begin{tabular}{cccc}
\hline Study & HA & $\boldsymbol{\alpha}$-TCP & $\boldsymbol{\beta}$-TCP \\
\hline Surface CaP precipitation in terms of area covered by precipitates (SBF study) [40] & Whole surface & Partially covered with precipitates \\
Alp gene expression levels of cells on materials (ALP enzymatic assay and RT-qPCR) & Strong & Weak & Medium \\
Degree of differentiation implied by proliferation study (DAPI staining) & High & Medium \\
In vivo bone formation in terms of incidence and quality of bone ${ }^{\text {a }}$ (by Yuan \& Zhang & Strong & Weak & Medium \\
et al) & (bone- & (bone- like tissue) \\
\hline
\end{tabular}

In order to make more reliable comparisons, the materials used in this project were synthesized in the same institute as in the previous report and made by the same method.
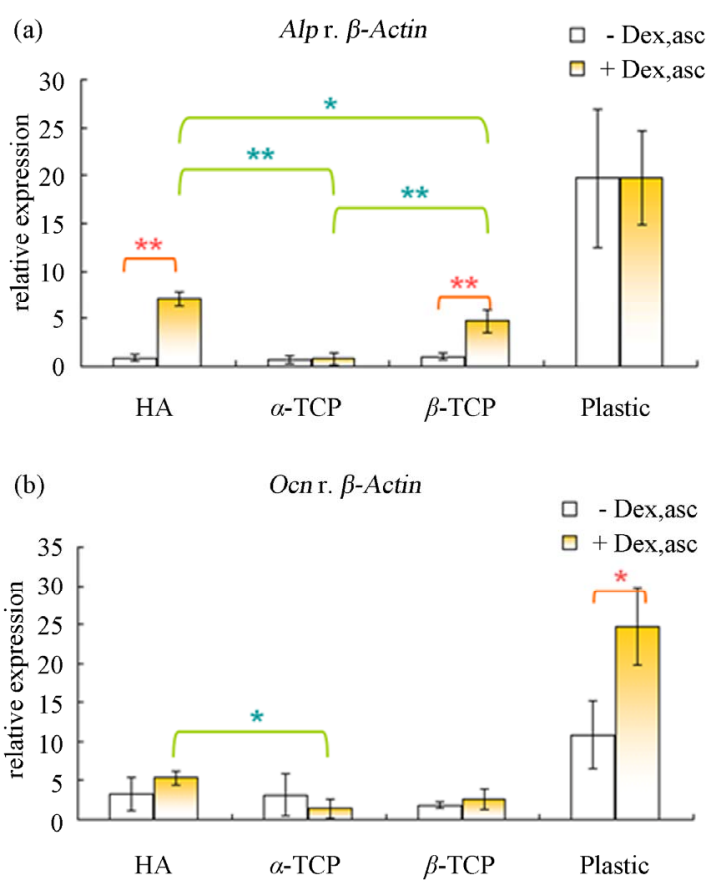

Figure 7. Relative quantification of gene expression of (a) Alp and (b) Ocn relative to $\beta$-Actin in 10T1/2 cells seeded on HA, $\alpha$-TCP and $\beta$-TCP after 6 days in culture with and without the addition of osteogenic supplements $\left(10^{-8} \mathrm{M}\right.$ dexamethasone and $50 \mu \mathrm{g} / \mathrm{mL} L$-ascorbic acid) (cDNA used for Ocn quantification was double that of $\mathrm{Alp})(\mathrm{n}=6$ PCR replicates for $\mathrm{Al} p$ from 2 batches of cDNA from same RNA, $\mathbf{n}=$ 3 PCR replicates for Ocn; mean \pm SD) $(* p<0.05$, **p $<$ 0.005).

confirms the suitability of using $10 \mathrm{~T} 1 / 2$ cells in cell culture inductivity study for more reproducible results.

\section{Acknowledgements}

We thank the constructive comments and technical assistances from members of the Bioengineering lab, Prof. King L. Chow lab, Prof. Yang Leng lab, the Materials Characterization and Preparation Facility, the Advanced Engineering Materials Facility of the Hong Kong Uni- versity of Science and Technology and the National Engineering Research Center for Biomaterials in Sichuan University. This work was financially supported by the Research Project Competition launched by the Hong Kong University of Science and Technology (Grant No. RPC 07/08.EG02) and the Research Grants Council (Grant no. HKUST 660407).

\section{REFERENCES}

[1] K. A. Hing, “Bioceramic Bone Graft Substitutes: Inflence of Porosity and Chemistry," International Journal of Applied Ceramic Technology, Vol. 2, No. 3, 2005, pp. 184-199. doi:10.1111/j.1744-7402.2005.02020.x

[2] P. Habibovic and K. de Groot, "Osteoinductive Biomaterials-Properties and Relevance in Bone Repair." Journal of Tissue Engineering and Regenerative Medicine, Vol. 1, No. 1, 2007, pp. 25-32. doi:10.1002/term.5

[3] R. Z. Legeros, S. Lin, R. Rohanizadeh, D. Mijares and J. P. Legeros, "Biphasic Calcium Phosphate Bioceramics: Preparation, Properties and Applications," Journal of Materials Science: Materials in Medicine, Vol. 14, No. 3, 2003, pp. 201-209. doi:10.1023/A:1022872421333

[4] R. Z. LeGeros, "Calcium Phosphate-Based Osteoinductive Materials," Chemical Reviews, Vol. 108, No. 11, 2008, pp. 4742-4753. doi:10.1021/cr800427g

[5] F. Bronner, M. C. Farach-Carson and A. G. Mikos, "Engineering of Functional Skeletal Tissues," Springer, Berlin, Vol. 3, 2007, pp. 1-178.

[6] M. F. Pittenger, A. M. Mackay, S. C. Beck, R. K. Jaiswal, R. Douglas, J. D. Mosca, M. A. Moorman, D. W. Simonetti, S. Craig and D. R. Marshak, "Multilineage Potential of Adult Human Mesenchymal Stem Cells," Science, Vol. 284, No. 5411, 1999, pp. 143-147. doi:10.1126/science.284.5411.143

[7] W. A. Silva Jr., D. T. Covas, R. A. Panepucci, R. ProtoSiqueira, J. L. C. Siufi, D. L. Zanette, A. R. D. Santos and M. A. Zago, "The Profile of Gene Expression of Human Marrow Mesenchymal Stem Cells," Stem Cells, Vol. 21, No. 6, 2003, pp. 661-669.

doi:10.1634/stemcells.21-6-661 
[8] N. Jaiswal, S. E. Haynesworth, A. I. Caplan and S. P. Bruder, "Osteogenic Differentiation of Purified, Culture-Expanded Human Mesenchymal Stem Cells in Vitro," Journal of Cellular Biochemistry, Vol. 64, No. 2, 1997, pp. 295-312.

doi:10.1002/(SICI)1097-4644(199702)64:2<295::AID-JC B12>3.0.CO;2-I

[9] H. Yuan, Z. Yang, J. D. De Bruijn, K. De Groot and X. Zhang, "Material-Dependent Bone Induction by Calcium Phosphate Ceramics: A 2.5-Year Study in Dog," Biomaterials, Vol. 22, No. 19, 2001, pp. 2617-2623. doi:10.1016/S0142-9612(00)00450-6

[10] J. T. Y. Lee, W. H. Tsang and K. L. Chow, "Simple Modifications to Standard TRIzol ${ }^{\circledR}$ Protocol Allow HighYield RNA Extraction from Cells on Resorbable Materials," Journal of Biomaterials and Nanobiotechnology, Vol. 2, No. 1, 2011, pp. 41-48. doi:10.4236/jbnb.2011.21006

[11] Y. Dohi, M. Akahane and H. Ohgushi, "Molecular Structure of Osteocalcin and the Role as An Essential Marker in the Osteogenic Differentiation Cascade," Journal of Nara Medical Association, Vol. 59, No. 3-4, 2008, pp. 83-96.

[12] J. B. Lian, G. S. Stein, A. Javed, A. J. Van Wijnen, J. L. Stein, M. Montecino, M. Q. Hassan, T. Gaur, C. J. Lengner and D. W. Young, "Networks and Hubs for the Transcriptional Control of Osteoblastogenesis," Reviews in Endocrine and Metabolic Disorders, Vol. 7, No. 1-2, 2006, pp. 1-16. doi:10.1007/s11154-006-9001-5

[13] J. B. Lian and G. S. Stein, "Runx2/Cbfa1: A Multifunctional Regulator of Bone Formation," Current Pharmaceutical Design, Vol. 9, No. 32, 2003, pp. 2677-2685. doi:10.2174/1381612033453659

[14] S. Maeno, Y. Niki, H. Matsumoto, H. Morioka, T. Yatabe, A. Funayama, Y. Toyama, T. Taguchi and J. Tanaka, "The Effect of Calcium Ion Concentration on Osteoblast Viability, Proliferation and Differentiation in Monolayer and 3D Culture," Biomaterials, Vol. 26, No. 23, 2005, pp. 4847- 4855. doi:10.1016/j.biomaterials.2005.01.006

[15] M. M. Dvorak, A. Siddiqua, D. T. Ward, D. H. Carter, S. L. Dallas, E. F. Nemeth and D. Riccardi, "Physiological Changes in Extracellular Calcium Concentration Directly Control Osteoblast Function in the Absence of Calciotropic Hormones," Proceedings of the National Academy of Sciences of the United States of America, Vol. 101, No. 14, 2004, pp. 5140-5145. doi: $10.1073 /$ pnas.0306141101

[16] M. M. Dvorak and D. Riccardi, " $\mathrm{Ca}_{2}^{+}$as an Extracellular Signal in Bone," Cell Calcium, Vol. 35, No. 3, 2004, pp. 249-255. doi:10.1016/j.ceca.2003.10.014

[17] M. Ahlstrom, M. Pekkinen, U. Riehle and C. LambergAllardt, "Extracellular Calcium Regulates Parathyroid Hormone-Related Peptide Expression in Osteoblasts and Osteoblast Progenitor Cells," Bone, Vol. 42, No. 3, 2008, pp. 483-490. doi:10.1016/j.bone.2007.10.025

[18] T. L. Arinzeh, T. Tran, J. Mcalary and G. Daculsi, "A
Comparative Study of Biphasic Calcium Phosphate Ceramics for Human Mesenchymal Stem-Cell-Induced Bone Formation," Biomaterials, Vol. 26, No. 17, 2005, pp. 3631-3638. doi:10.1016/j.biomaterials.2004.09.035

[19] C. G. Bellows, J. N. M. Heersche and J. E. Aubin, "Inorganic Phosphate Added Exogenously or Released from $\beta$-Glycerophosphate Initiates Mineralization of Osteoid nodules in Vitro," Bone and Mineral, Vol. 17, No. 1, 1992, pp. 15-29. doi:10.1016/0169-6009(92)90707-K

[20] C. S. Adams, K. Mansfield, R. L. Perlot and I. M. Shapiro, "Matrix Regulation of Skeletal Cell Apoptosis. Role of Calcium and Phosphate Ions," Journal of Biological Chemistry, Vol. 276, No. 23, 2001, pp. 20316- 20322. doi:10.1074/jbc.M006492200

[21] Z. Meleti, I. M. Shapiro and C. S. Adams, "Inorganic phosphate Induces Apoptosis of Osteoblast-Like Cells in Culture," Bone, Vol. 27, No. 3, 2000, pp. 359-366. doi:10.1016/S8756-3282(00)00346-X

[22] J. Chen, J. Weng, Q. Zhang, J. Feng, Y. Cao and X. Zhang, "Effect of Post-Treatment on Dissolution and Biomineralization on Surface of HA Coatings in Simulated Body Fluid (SBF)," Materials Research Society Symposium - Proceedings, Vol. 599, 2000, pp. 55-60.

[23] R. Detsch, H. Mayr and G. Ziegler, "Formation of Osteoclast-Like Cells on HA and TCP Ceramics," Acta Biomaterialia, Vol. 4, No. 1, 2008, pp. 139-148. doi:10.1016/j.actbio.2007.03.014

[24] S. Langstaff, M. Sayer, T. J. N. Smith and S. M. Pugh, "Resorbable Bioceramics Based on Stabilized Calcium Phosphates. Part II: Evaluation of Biological Response," Biomaterials, Vol. 22, No. 2, 2001, pp. 135-150. doi:10.1016/S0142-9612(00)00139-3

[25] R. Tang, M. Hass, W. Wu, S. Gulde and G. H. Nancollas, "Constant Composition Dissolution of Mixed Phases II. Selective Dissolution of Calcium Phosphates," Journal of colloid and Interface Science, Vol. 260, No. 2, 2003, pp. 379-384. doi:10.1016/S0021-9797(03)00048-1

[26] T. Suzuki, T. Yamamoto, M. Toriyama, K. Nishizawa, Y. Yokogawa, M. R. Mucalo, Y. Kawamoto, F. Nagata and T. Kameyama, "Surface Instability of Calcium Phosphate Ceramics in Tissue Culture Medium and the Effect on Adhesion and Growth of Anchorage-Dependent Animal Cells," Journal of Biomedical Materials Research, Vol. 34, No. 4, 1997, pp. 507-517. doi:10.1002/(SICI)1097-4636(19970315)34:4<507::AIDJBM11>3.0.CO;2-9

[27] X. Lu and Y. Leng, "Theoretical Analysis of Calcium Phosphate Precipitation in Simulated Body Fluid," Biomaterials, Vol. 26, No. 10, 2005, pp. 1097-1108. doi:10.1016/j.biomaterials.2004.05.034

[28] S. V. Dorozhkin and M. Epple, "Biological and Medical Significance of Calcium Phosphates," Angewandte Chemie-International Edition, Vol. 41, No. 17, 2002, pp. 3130-3146.

doi:10.1002/1521-3773(20020902)41:17<3130::AID-AN IE3130>3.0.CO;2-1 
[29] M. Vallet-Regí and J. M. González-Calbet, "Calcium Phosphates as Substitution of Bone Tissues," Progress in Solid State Chemistry, Vol. 32, No. 1-2, 2004, pp. 1-31. doi:10.1016/j.progsolidstchem.2004.07.001

[30] Ferńndez E., F. J. Gil, M. P. Ginebra, F. C. M. Driessens, J. A. Planell and S. M. Best, "Calcium Phosphate Bone Cements for Clinical Applications. Part I: Solution Chemistry," Journal of Materials Science: Materials in Medicine, Vol. 10, No. 3, 1999, pp. 169-176. doi:10.1023/A:1008937507714

[31] R. Garimella, J. B. Sipe and H. C. Anderson, "A Simple and Non-Radioactive Technique to Study the Effect of Monophosphoesters on Matrix Vesicle-Mediated Calcification," Biological Procedures Online, Vol. 6, No. 1, 2004, pp. 263-267. doi:10.1251/bpo97

[32] K. Hamada, M. Kon, T. Hanawa, K. Yokoyama, Y. Miyamoto and K. Asaoka, "Hydrothermal Modification of Titanium Surface in Calcium Solutions," Biomaterials, Vol. 23, No. 10, 2002, pp. 2265-2272. doi:10.1016/S0142-9612(01)00361-1

[33] E. A. dos Santos, M. Farina, G. A. Soares and K. Anselme, "Chemical and Topographical Influence of Hydroxyapatite and Beta-Tricalcium Phosphate Surfaces on Human Osteoblastic Cell Behavior," Journal of biomedical materials research. Part A, Vol. 89, No. 2, 2009, pp. 510-520. doi:10.1002/jbm.a.31991

[34] G. C. Reilly, S. Radin, A. T. Chen and P. Ducheyne, "Differential Alkaline Phosphatase Responses of Rat and Human Bone Marrow Derived Mesenchymal Stem Cells to 45S5 Bioactive Glass," Biomaterials, Vol. 28, No. 28, 2007, pp. 4091-4097. doi:10.1016/j.biomaterials.2007.05.038

[35] E. A. Abou Neel, T. Mizoguchi, M. Ito, M. Bitar, V. Salih and J. C. Knowles, "In Vitro Bioactivity and Gene Expression by Cells Cultured on Titanium Dioxide Doped Phosphate-Based Glasses," Biomaterials, Vol. 28, No. 19, 2007, pp. 2967-2977. doi:10.1016/j.biomaterials.2007.03.018

[36] M. A. Aronow, L. C. Gerstenfeld, T. A. Owen, M. S. Tassinari, G. S. Stein and J. B. Lian, "Factors that Promote Progressive Development of the Osteoblast Phenotype in Cultured Fetal Rats Calvaria Cells," Journal of Cellular Physiology, Vol. 143, No. 2, 1990, pp. 213-221.

[37] A. J. Engler, S. Sen, H. L. Sweeney and D. E. Discher, "Matrix Elasticity Directs Stem Cell Lineage Specification," Cell, Vol. 126, No. 4, 2006, pp. 677-689. doi:10.1016/j.cell.2006.06.044

[38] C. Desbois, D. A. Hogue and G. Karsenty, "The Mouse Osteocalcin Gene Cluster Contains Three Genes with Two Separate Spatial and Temporal Patterns of Expression," Journal of Biological Chemistry, Vol. 269, No. 2, 1994, pp. 1183-1190.

[39] S. Rahman, A. Oberdorf, M. Montecino, S. M. Tanhauser, J. B. Lian, G. S. Stein, P. J. Laipis and J. L. Stein, "Multiple Copies of the Bone-Specific Osteocalcin Gene in Mouse and Rat," Endocrinology, Vol. 133, No. 6, 1993, pp. 3050-3053. doi:10.1210/en.133.6.3050 